\title{
KNOWLEDGE, ATTITUDE AND PERCEPTION TOWARD EVIDENCE BASED MEDICINE AMONG MEDICAL STUDENTS IN SHENDI UNIVERSITY- SUDAN
}

\author{
Naba'a Alkhair ALshaikh ${ }^{1}$, Haghamad Allzain ${ }^{* 2}$ (iD), Bashier Eltayeb Shumo ${ }^{1}$ iD \\ 1 Department of Community Medicine, Faculty of Medicine, Shendi University, Sudan \\ ${ }^{*} 2$ Department of Biochemistry, Faculty of Medicine, Shendi University, Sudan
}

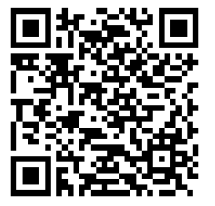

DOI: https://doi.org/10.29121/granthaalayah.v9.i3.2021.3773

Article Type: Research Article

Article Citation: Naba'a Alkhair ALshaikh, Haghamad Allzain, and Bashier Eltayeb Shumo. (2021). KNOWLEDGE, ATTITUDE AND PERCEPTION TOWARD EVIDENCE BASED MEDICINE AMONG MEDICAL STUDENTS IN SHENDI UNIVERSITY- SUDAN. International Journal of Research GRANTHAALAYAH, 9(3), 149-155. https://doi.org/10.29121/granthaa layah.v9.i3.2021.3773

Received Date: 02 March 2021

Accepted Date: 30 March 2021

Keywords:

Evidence

Medicine

Knowledge

Attitude

Perception

Cochrane

\section{Abbreviations}

EBM, Evidence-based medicine; EBP, Evidence-Based Practice ; UK, United Kingdom; RCR, Randomized Controlled Research ; SPSS, Statistical Package for Social Sciences; WHO, World Health Organization.

\section{ABSTRACT}

Evidence-based medicine (EBM) is the "conscientious, explicit, and judicious use of current best evidence (Thamer Z. et al. 2018 .It is the evolving science of clinical care. It is the judicious use of the best current evidence in making decisions about the care of the individual patient. It also integrates clinical expertise, patient desires, values, and needs . (Michael LeFevre.2014)

The current study intended to assess Knowledge, attitude and perception toward EBM among medical students in Shendi University in Sudan. It was descriptive cross-sectional one, from October to December 2020; It included one hundred and twenty one (121) medical students. Data was collected employing structural self -administered questionnaire and the data collected was analyzed by SPSS.

The findings of the study described the current status of level of awareness and use of EBM .More than half of students have poor knowledge toward EBM. Approximately half or less have good attitude compared with their poor knowledge, while the perception of the importance of evidence based medicine was good (72\%). 
Knowledge, Attitude and Perception Toward Evidence Based Medicine Among Medical Students in Shendi UniversitySudan

\section{INTRODUCTION}

Innovation in information technology alongside massive increase in biomedical research has given rise to changing biomedical literature varying in quality and clinical relevance. Also the increasing utilization of social media in reflective peer-to-peer learning and the media manipulation encountered. This has led to the adoption of evidence-based medicine (EBM) as the new paradigm for medical practice (Francisco Jose Grajales, et al .2014 ;Jens R. Chapman, et al 2018).

The term EBM was coined by Gordon Guyatt in 1992, which is based on the integration of research, patient preferences, and clinical experience. EBM's placing the practice of medicine on a solid scientific basis (EBM Working Group. 1992). It promotes the development of more sophisticated hierarchies of evidence, the recognition of the crucial role of patient values and preferences in clinical decision making, and the development of the methodology for generating trustworthy recommendations (Benjamin Djulbegovic \& Gordon H Guyatt. 2017) . David Lawrence Sackett a clinical epidemiologist, and founding Chair of the Cochrane Collaboration is widely regarded as a pioneer and the father of EBM. Sackett and his colleagues focused on the need to not only teach methods to understand the scientific literature but also to teach the application of new information to the physicians. It has been described as one of the most important medical advancements in the past one hundred and fifty (150) years, alongside the discovery of vaccines and antibiotics.

The Cochrane Collaboration is a non-profit organization established in (1993) in the UK. (H V Worthington, et al 2013). It comprises over ten thousand $(10,000)$ scientist worldwide. Its main mission is to go through and prepare systematic reviews of new research that is being published every day in various specialties based on the strongest evidence available, in order to help make informed decisions on healthcare interventions for the best possible patient outcome (I Taylor, et al .2017) .

EBM represents integration of clinical expertise, patient's values and best available evidence in process of decision making related to patients health care (IzetMasic, etal. 2008). It is one of these essential elements of practice becoming part of medical curricula around the world (Mylene Lévesque, et al 2018).

EBM has thus become an impetus for incorporating a critical appraisal of research evidence alongside routine clinical practice. The acquisition of knowledge and skills for EBM is becoming a core competence for all doctors. There is an increasing emphasis on the teaching of EBM skills in undergraduate, postgraduate, and continuing medical education programs (Thamer Z.et al 2018).

The main reason for practicing EBM is to improve quality of care through the identification and promotion of practices that work, and the elimination of those that are ineffective or harmful. EBM promotes critical thinking, and important for health care professionals to develop key EBM skills, including the ability to find, critically appraise, and incorporate sound scientific evidence into their own practice (A K Akobeng. 2005)

The practice of evidence-based medicine is a process of lifelong, self-directed, problem-based learning in which caring for one's own patients creates the need for clinically important information about diagnosis, prognosis, therapy and other clinical and health care issues. Its good application brings cost-effective and better health care. The key difference between EBM and traditional medicine is not that EBM considers the evidence while the latter does not. Both take evidence into account; however, EBM demands better evidence than has traditionally been used (Izet Masic, et al .2008)

As EBM is a "conscientious, explicit and judicious use of current best evidence in making decisions about the care of an individual patient, its teaching is recommended as an essential part of medical/clinical education (van Buljan, etal 2018).

The need and demand for evidence based practice in health care is growing rapidly because of information overload, rising patient expectations, new and advanced technologies and aging population.. The practice of EBM involves formulating answerable clinical questions, finding, appraising and applying the evidence and evaluating performance (Farley library research guides. 2020, Centre for EBM. 2020).

Therefore, EBM is a conceptual approach of the physician in making decisions related to the individual patient. Unlike this, evidence-based health care is somewhat broader concept that includes advanced approach to understanding the patients, families and doctors' beliefs, values and attitudes. It also relies on evidence, but primarily those on population level (Izet Masic , et al .2008). 
Evidence needs to realize that it is a tool in the toolbox to inform doctors but to have any credibility it needs to be used on a scale and in a way which generates real confidence (Editorials.2017). Therefore evidence levels can be classified into evidences obtained from:

1) (1a) Meta-analysis of several randomized controlled research (RCR).

2) (1b) Only one randomized controlled research RCR.

3) (2a) Well-designed controlled research RCR.

4) (2b) One quasi experimental research.

5) (3) Non-experimental studies (comparative research, case study), according to some, for example Textbooks.

6) (4) Experts and clinical practice (Dang, D. \& Dearholt, S.L. 2018).

Hierarchy of evidence is the levels of evidence assigned to studies based on the methodological quality of their design, validity and applicability to patient care (Darrell .W.2020). It provides a framework for ranking evidence that evaluates health care interventions and indicates which studies should be given most weight in an evaluation where the same question has been examined using different types of study (Elizabeth Ayetley, et al 2016).

Evidence-based practice (EBP) is believed to be associated with improved health, safety, and cost outcomes. Most medical practice in low- and middle-income countries is not evidence-based (Getenet Dessie, et al 2020).

Healthcare decisions are increasingly being based upon research-derived evidence, rather than on expert opinion or clinical experience alone, although Interpreting and understanding evidence synthesis, systematic reviews and other analytic literature is a difficult task. (Laxmaiah Manchikanti-, et al 2007; J C Craig, et al .2001)

\section{RATIONALE}

EBM is an essential method of teaching that is applied in clinical decision making, therefore studying of knowledge, attitude and perception of EBM among medical students help to evaluate their knowledge and ability to use EBM to improve the quality of health care.

This research will help emphasize the importance of applying EBM in the curriculum of medical students.

The objective of this study to evaluate Knowledge, attitude and perception toward EBM among medical students in Shendi University in Sudan.

\section{METHODOLOGY}

The current study was descriptive cross-sectional one, carried out from October to December 2020 in the Faculty of Medicine in Shendi University in Sudan. It included one hundred and twenty one (121) medical students, as non probability convenience sample. Data was collected by individual interviewing, self- administrated questionnaire and analyzed by the soft ware SPSS for windows version (22).The references were managed manually using Harvard style.

\section{ETHICAL CONSIDERATION}

The study was approval by the department of community medicine in the Faculty of Medicine - Shendi University.

\section{RESULTS}

Table 1: The knowledge statements

\begin{tabular}{|c|c|c|c|c|c|c|}
\hline \multicolumn{6}{|c|}{ Statement (1.1): Clinical expertise is one of the three components of Evidence-based medicine. (No. 121) } \\
\hline Frequency & $\begin{array}{c}\text { Famous } \\
\text { text books }\end{array}$ & $\begin{array}{c}\text { WHO } \\
\text { reports }\end{array}$ & Senior opinions & $\begin{array}{c}\text { Evidences } \\
\text { Patient's } \\
\text { choice }\end{array}$ & Multiple options \\
\hline Percentage & $14 \%$ & $10 \%$ & $9 \%$ & $9 \%$ & $1 \%$ & $57 \%$ \\
\hline \multicolumn{7}{|c|}{ Statement (1.2) : Strongest evidence' in the EBM concept. (No. 121) } \\
\hline
\end{tabular}


Knowledge, Attitude and Perception Toward Evidence Based Medicine Among Medical Students in Shendi UniversitySudan

\begin{tabular}{|c|c|c|c|c|}
\hline Frequency & $\begin{array}{c}\text { Systematic } \\
\text { Review }\end{array}$ & Cross sectional Study & $\begin{array}{c}\text { Cohort } \\
\text { Study }\end{array}$ & Longitudinal Study \\
\hline Percentage & $35 \%$ & $33 \%$ & $26 \%$ & $6 \%$ \\
\hline \multicolumn{2}{|c|}{ Statement (1.2) : Knowing Cochrane library. (No. 121) } \\
\hline Frequency & Yes & No \\
\hline Percentage & $25 \%$ & $75 \%$ \\
\hline
\end{tabular}

Table 2: The attitude statements

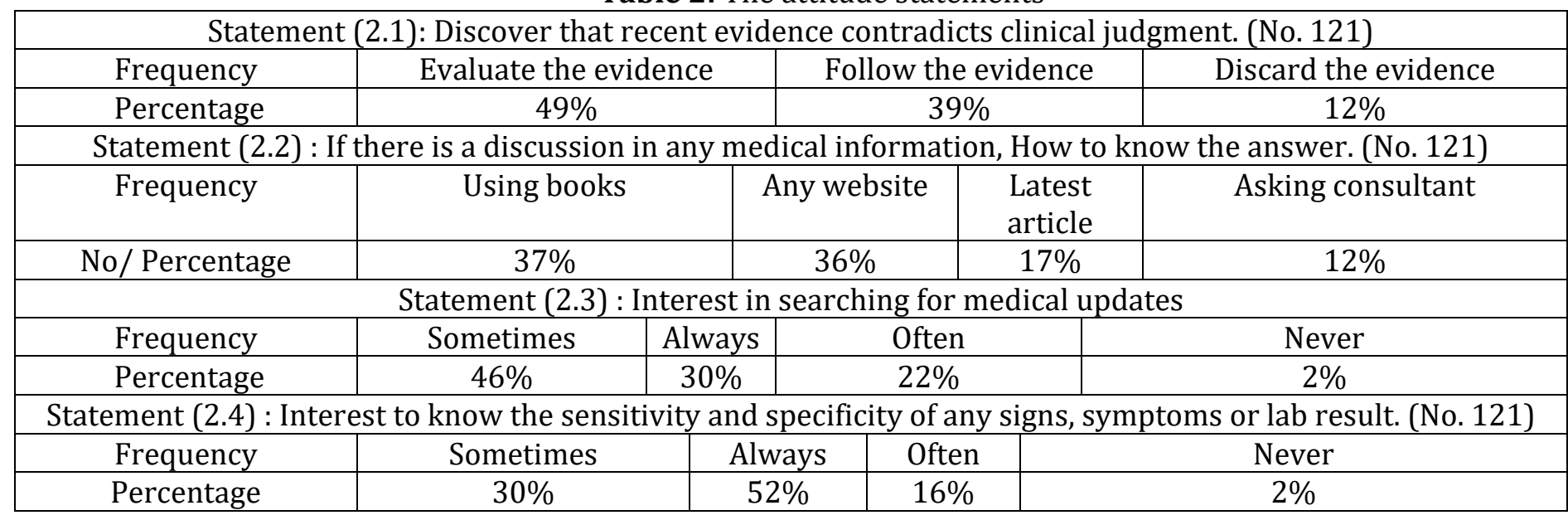

Table 3: The perception statements

Statement (3.1): Agreement of important of EBM during undergraduate medical education. (No. 121)

\begin{tabular}{l|c|c|c} 
Frequency & Agree & Neutral & Disagree \\
\hline Percentage & $72 \%$ & $27 \%$ & $1 \%$
\end{tabular}

Statement (3.2) : Believe in patients willing to participate in clinical decision making. (No. 121)

\begin{tabular}{|c|c|c|c}
\hline Frequency & Sometimes & Always & Never \\
Percentage & $66 \%$ & $26 \%$ & $8 \%$ \\
\hline
\end{tabular}

\section{DISCUSSION}

This study was cross-sectional descriptive, conducted in Shendi University to assess evidence based medicine knowledge, attitude and perception among students; the study population were medical students.

Clinical expertise is one of the three components of Evidence-based medicine the answers were 14\% for (Famous text book), 10\% for (WHO reports), 9\% for (senior consultant's opinion, Evidences,) and 9\% for (Your patient's choice).The multiple options answers were 17\% for (Evidence+ WHO reports), 10\% for (Evidences+ the patient's choice), 9\% for (Famous text books + senior consultant's opinion), 6\% for (Famous text books + WHO reports), $5 \%$ for (senior consultant's opinion + Evidences), 3\% for (Famous text book + Evidence), 3\% for (WHO reports + the patient's choice), $2 \%$ for (senior consultant's opinion + Who reports), $1 \%$ for (Famous text books + the patient's choice) and also 1\% for (Famous text books + senior consultant's opinion).

$35 \%$ of the students know that systematic review is what provide the strongest evidence in 'Hierarchy of Evidence' in evidence based medicine concept In another study in Saudi Arabia in the same article 40.4\% appreciated that the strongest evidence to EBP is systematic review (Thamer Z. et al 2018).

Students when asked if they know Cochrane library75\% of them said no and 25\% said yes, in comparison with students in Saudi Arabia when asked the same question 95\% of the respondents were not aware of the Cochrane Library (CL), so regarding to that the level of knowledge about Cochrane library in Shendi university was good (Thamer Z. et al 2018).

When students asked if they discover that recent evidence contradicts clinical judgment what will they do 49\% will (Evaluate the evidence), 39\% said that they will(Follow the evidence) and 12\% go with (Discard the evidence). 
Using books was the choice of $37 \%$ of students and $36 \%$ said they will find out information from any websites , $15 \%$ said (Seeing the latest article) and $12 \%$ said (Asking your consultant) as an answer about If there is a discussion in any medical information, what will they do to know the answer, when the same question was asked to medical students of king Abdulaziz university in Saudi Arabia 7.1\% said (Using books), 0\%said (Find out from any website), $50 \%$ said (Seeing the latest article) and $42 \%$ said (Asking your consultant) (HussamAlbugami, et al. 2017).

Students were asked if they interested in searching for medical updates $46 \%$ said (Sometimes), 30\% for (Always), 22\% for (Often) and 2\% for (Never), other study in the same article made in king abdulaziz university students respond to same question with different choices were $92.9 \%$ for (yes) and 7.1\% for (no) (HussamAlbugami, et al. 2017)..

About the interesting of the students to know the sensitivity and specificity of any signs, symptoms or lab result $52 \%$ says they always interested about knowing it, in the other side $78 \%$ of king abdulaziz university students also have the interested to know (HussamAlbugami, et al. 2017).

$72 \%$ of the students agree when they asked about their agreement of important of EBM during undergraduate education, $27 \%$ were Neutral and $1 \%$ disagree.

More than half of students (66\%) think they (Sometimes) patients are willing to participate in clinical decision making, $26 \%$ said patient are (Always) in the other side $87.1 \%$ of medical students in deferent universities in Saudi Arabia says (Yes) for the participation of patients in clinical decision making(Thamer Z. et al 2018).

Students were asked if they have an account in any medical database library as question to assess their attitude and perception about EBM 59\% said (No) and 41\% said (Yes) (HussamAlbugami, et al. 2017).

The knowledge of the medical student of Shendi university about EBM was poor.

Their attitude toward it was good but not the best and that mostly because of the poor knowledge of them about EBM.

Their perception was significantly good especially about the important of the EBM and that may increase their interest to get more knowledge about it

\section{CONCLUSION}

The findings of this study described the current status of level of awareness and use of EBM among the medical students. More than half of students have poor knowledge toward evidence based medicine, and approximately half have good attitude compared with their poor knowledge ,while the perception of the importance of EBM was good $(72 \%)$.

\section{RECOMMENDATIONS}

It was recommended that EBM to be incorporated in medical schools curricula and to raise the awareness of the students about it, as new concept for contemporary and future medical practices.

\section{Authors, contributions}

1) Dr .Naba'a Alkhair ALshaikh: the principal investigator collected the data, interpreted the data generated.

2) Dr. Haghamad Allzain : wrote and enriched the manuscript.

3) Dr. Bashier Eltayeb Shumo: the supervisor of the research, conceived the idea, provide critical suggestions, and follow up the course of the research.

\section{SOURCES OF FUNDING}

This research received no specific grant from any funding agency in the public, commercial, or not-for-profit sectors. 
Knowledge, Attitude and Perception Toward Evidence Based Medicine Among Medical Students in Shendi UniversitySudan

\section{CONFLICT OF INTEREST}

The author have declared that no competing interests exist.

\section{ACKNOWLEDGMENT}

The authors appreciated the participation of the medical students in Shendi University in the study, many thanks to you all for your precious time.

\section{REFERENCES}

[1] A K Akobeng. (2005). Evidence based child health 1. Principles of evidence based medicine, page 837

[2] Benjamin Djulbegovic \& Gordon H Guyatt (2017). Progress in evidence-based medicine: a quarter century on. The Lancet. Volume 390, Issue 10092, 22-, Pages 415-423

[3] Centre for Evidence-Based Medicine. (2020) .Finding the evidence: a how-to guide.

[4] Dang, D., \& Dearholt, S.L. (2018). Johns Hopkins nursing evidence-based practice : Model \& guidelines (3rd ed). Sigma Theta Tau International.

[5] Darrell W. (2020) .Kruger Library Winona State University, Evidence Based Practice Toolkit.

[6] Editorials (2017) .Evidence based medicine manifesto for better healthcare. BMJ;357:j2973.

[7] Elizabeth A Yetley, Amanda J MacFarlane, Linda S Greene-Finestone, et al. (2017 Jan) Options for basing Dietary Reference Intakes (DRIs) on chronic disease endpoints: report from a joint US-/Canadian-sponsored working group . Am J Clin Nutr. ; 105(1): 249S-285S

[8] Evidence-Based Medicine Working Group. (1992) .Evidence-based medicine. A new approach to teaching the practice of medicine. JAMA.;268:2420-2425. doi:10.1001/jama.268.17.2420.

[9] Farley library research guides. (2020). Evidence practice and information mastery: clinical question and PICO method.

[10] Getenet Dessie, Dube Jara , Girma Alem, Henok Mulugeta, Tesfu Zewdu, Fasil Wagnew , Rachel Bigley , Sahai Burrowes (2020) ,Evidence-Based Practice and Associated Factors Among Health Care Providers Working in Public Hospitals in Northwest Ethiopia During. 2017. Curr Ther Res Clin Exp. ; 93: 100613.

[11] Grajales III FJ, Sheps S, Ho K, Novak-Lauscher H, Eysenbach G. (2014)

[12] Social Media: A Review and Tutorial of Applications in Medicine and HealthCare. JMed Internet Res;16(2):e13

[13] doi: 10.2196/jmir.2912PMID: 24518354PMCID: 3936280

[14] H V Worthington , A-M Glenny, J E Clarkson (2013) .Twenty years of the Cochrane Collaboration . J Dent Res ;92(8):680-1.

[15] HussamAlbugami, QusayMandoorah, Ayman ZakyElsamanoudy and Mohammed Ahmed Hassanien, (2017) .Evaluation of Evidence Based Medicine Knowledge and Skills among a Sample of Medical Students in King Abdul Aziz University: A Follow up Study, British Journal of Medicine \& Medical Research . page 7

[16] IzetMasic, Milan Miokovic, Belma Muhamedagic. (2008). Evidence based medicine - New approaches and challenges, Professional Paper. 16:219

[17] J C Craig , L M Irwig, M R Stockler (2001) . Evidence-based medicine: useful tools for decision making .Med J Aust . 5;174(5):248-53.

[18] J Taylor, T Walsh, H Worthington, P Brocklehurst, M N Pemberton , A M Glenny. (2017) Cochrane and the COMET initiative: developing the evidence base in oral medicine . Br Dent J .;223(9):729-732.

[19] Jens R. Chapman, Karsten Wiechert, and Jeffrey C. (2018) Wang, Evidence-Based Medicine, Media, and Manipulation. Global Spine J. ; 8(5): 437-439.

[20] Laxmaiah Manchikanti , Mark V Boswell, James Giordano (2007) .Evidence-based interventional pain management: principles, problems, potential and applications .Pain Physician .;10(2):329-56.

[21] Michael LeFevre.(2017) From authority- to evidence-based medicine: are clinical practice guidelines moving us forward or backward. The Annals of Family Medicine ., 15 (5) 410-412 
[22] Mylene Lévesque, Janie Gauthier-Boudreau, Paul Gagnon, Bastian Bertulies-Esposito, Sharon Hatcher, Louis Gagnon. (2018). Evaluation of an evidence-based medicine educational intervention in a regional medical campus, Canadian Medical Education Journal,9:e52

[23] Thamer Z. Aldugieman, Rawabi S. Alanezi, Wasmiah M. G. Alshammari, Yasmeen W. Z. Al Shamary, Mishaal M. Alqahtani, Fayez S. Alreshidi (2018). Knowledge, attitude and perception toward evidence-based medicine among medical students in Saudi Arabia, Journal of Family Medicine and Primary Care, ,7:1026

[24] van Buljan, Ana Jerončić, Mario Malički, MatkoMarušić and Ana Marušić (2018). How to choose an evidencebased medicine knowledge test for medical students? Comparison of three knowledge measures, BMC Medical Education, page 1 